\title{
INFOPOINTS
}

\section{Whisking research into the classroom}

The marriage between research and teaching has been loving. Information from the laboratory is translated to the classroom to increase the wisdom of future generations. Conversely, students' questions sharpen our research. Disappointingly, the information flow from research to class is meandering. In one pathway, research results are re-written in books and then included in lectures. This is characteristic of undergraduate training. In a second route, faculties create their own lectures directly from the original articles, as in graduate teaching. Both approaches have worked well, but they are now ill equipped to handle the speed and quantity of scientific developments. Research and teaching are growing distant.

The lack of progress is seen by contrasting research 150 years ago with that today. John Snow in 1854 characterised cholera in London; the results were published a year later, and by 1856 the information was in undergraduate curriculums - only two years after the original epidemic. ${ }^{1}$ In contrast, research completed in 2002 may not be seen in classrooms for more than five years.

Another problem with producing lectures from original research literature is the information explosion. A typical introductory course for students has 30 topics, and it is impossible for a faculty to keep up with developments in five of these subjects, let alone 30. Students do not receive state of the art lectures.

A knowledge speedway is needed to pass information from research to classroom (and return feedback to the scientists). The internet would be its backbone, and one such method is a free, shareware system called the Supercourse, which provides lecture courses on epidemiology and the internet for students in medicine and health related subjects. ${ }^{2}$ Scientists put these web lectures in a library on the website, and currently 4700 faculty members from 141 countries have contributed 473 lectures.

Similar models could be developed for any discipline. Scientific journals on the web could create a lecture library on the internet to bridge the "translation gap" between research and teaching. The approach is simple: with each article accepted for publication, PowerPoint slides are provided that give the key results. A simple click would allow teachers worldwide to download the slides free of charge. Instead of it taking 1-4 years for scientific results to appear in the classroom, it would take 1-4 minutes. Potentially, this could be taken to a higher level with lecture buttons on Medline. An advantage for journal publishers is that such lectures would reach many more people than the journals, and thus might be a portal to pay-for-view articles.

The Supercourse Faculty can be accessed at www.pitt. $\mathrm{edu} / \sim$ super1. Authors of future $B M J$ papers who would like to place an associated talk on Supercourse should contact Supercourse direct. They should also tell the $B M J$ that a talk appears on Supercourse, so that a link can be made from the paper on bmj.com to the Supercourse site.

Ronald E Laporte director, disease monitoring and telecommunications

WHO Collaborating Center, 3512 Fifth Avenue, University of Pittsburgh, Pittsburgh, PA 15261, USA (ronlaporte@aol.com)

Akira Sekikawa assistant professor of epidemiology

EunRyoung Sa research fellow

Faina Linkov research fellow

Mita Lovalekar research fellow

Department of Epidemiology, Graduate School of Public Health, University of Pittsburgh

Competing interests: None declared.

1 UCLA Department of Epidemiology. John Snow. www.ph.ucla.edu epi/snow.html (accessed 16 Aug 2001).

2 Supercourse Faculty. Global cooperation in higher education. Nature Med 2000;6:358.

BMJ 2002;324:99

\section{One hundred years ago The red badge of vaccination}

The red band so frequently seen on the left arm of the man in the street at present naturally has an effect on the "antivacks" akin to that of the proverbial red rag on the bull. We note without surprise, therefore, that at the annual meeting of the General Council of the London Vegetarian Association, held the other day at the Memorial Hall, Farringdon Street, Mr. A. F. Hills, the President, who was in the chair, used strong language on the subject. He is reported to have said that it was absurd and distressing to see men and women walking about the streets with a piece of red ribbon on their arms, advertising the fact that they had taken into their bodies one disease in order to prevent the breaking out of another. This he thought must be regarded as a sad sign of the mental decrepitude of the people of our time. Vegetarians believed in no such nonsense. They believed that if only people would put their lives in harmony with God's eternal law of health there need be no fear of contracting small-pox or any other disease. He hoped vegetarians would do all in their power to counteract the false doctrine that people could be saved from one disease by the inoculation of another. All who looked carefully into the question would find that the medical statistics respecting the power of vaccination were fallacious, and it did not possess the value claimed for it in preventing a person contracting small-pox. We may perhaps be excused from dealing with the statistical part of Mr. Hills's remarks here. But we venture with all respect to ask for a little more light on his dark saying about "God's eternal law of health." Faddists are too ready to take the name of God in vain to support the sickly fancies bred in their own brains. Has Mr. Hills an atom of proof that vegetarians unprotected by vaccination are not as liable to small-pox as their carnivorous fellow creatures? If he has, we call upon him to produce it. If he has not, what right has he to delude the silly folk who listen to him into the belief that they need have "no fear of contracting small-pox or any other disease?" Does Mr. Hills seriously believe himself or the devotees of his cult to be above the common lot of humanity and invulnerable against disease? (BMJ 1902;i:349) 